\title{
Triagem fitoquímica e atividade antioxidante de Costus spicatus (Jacq.) S.w.
}

\author{
AZEVEDO, L.F.P. ${ }^{1 *}$; FARIA, T.S.A. ${ }^{1}$; PESSANHA, F.F. ${ }^{1}$; ARAUJO, M.F.' ${ }^{1}$ LEMOS, G.C.S. ${ }^{1}$ \\ ${ }^{1}$ Faculdade de Medicina de Campos - Avenida Alberto Torres, 217 - Centro CEP: Campos dos Goytacazes - \\ Brasil, */uisfernandopazv@gmail.com
}

\begin{abstract}
RESUMO: O objetivo do trabalho foi avaliar o perfil fitoquímico e a atividade antioxidante comparando-se os resultados obtidos entre diferentes órgãos da Costus spicatus. Foram utilizados caules, folhas e flores da Costus spicatus, colhidos na Universidade Estadual do Norte Fluminense Darcy Ribeiro, no município de Campos dos Goytacazes, RJ. Os diferentes órgãos foram avaliados quanto ao perfil fitoquímico e atividade antioxidante nas frações hexânica, acetato de etila e butanólica. Os resultados obtidos comprovaram a presença de Triterpenos e Esteróides (Lieberman-Burchard), Flavonóides (Shinoda), Saponinas (Índice de espuma), Alcalóides (Drangendorff) e Taninos (Cloreto Férrico). Foi demonstrada a atividade antioxidante potencial. Concluiu-se que a Costus spicatus apresentou todas as classes de metabólitos pesquisadas, dentre as quais, algumas possuem atividade biológica já conhecida, fazendo-se necessária a realização de estudos quantitativos e pesquisas que demonstrem seus efeitos farmacológicos, contribuindo para o desenvolvimento de novos fármacos.
\end{abstract}

Palavras-chave: Antioxidantes. Costus spicatus. Triagem fitoquímica.

ABSTRACT: Phytochemical screening and antioxidant activity of Costus spicatus (Jacq.) Sw. The objective of this work was to evaluate the phytochemical profile and the antioxidant activity comparing the results between different organs of Costus spicatus. We used the stems, leaves and flowers of Costus spicatus harvested at the State University of Norte Fluminense "Darcy Ribeiro" in the city of Campos dos Goytacazes, Rio de Janeiro, Brazil. The different organs were evaluated for antioxidant activity and phytochemical profile in the hexane, ethyl acetate and butanol fractions. The results obtained proved the presence of triterpenes and steroids (Liebermann-Burchard), flavonoids (Shinoda), saponins (foaming index), alkaloids (Dragendorff) and tannins (ferric chloride). We demonstrated the potential antioxidant activity. We concluded that Costus spicatus presented all classes of metabolites studied, among which some already have their biological activity known by the literature, being necessary the performance of quantitative and research studies that demonstrate their pharmacological effects, thus contributing to the development of new drugs.

Keywords: Antioxidants. Costus spicatus. Phytochemical screening.

\section{INTRODUÇÃO}

O uso de plantas medicinais tem sido largamente empregado no tratamento e prevenção de doenças pela população nos últimos anos. Durante milênios os povos indígenas de todo mundo vem utilizando plantas com fins medicinais e estes conhecimentos foram transmitidos por gerações até se difundirem com o surgimento das civilizações modernas (Rezende et al, 2004). Dessa forma, a comunidade científica mundial vem trabalhando no intuito de comprovar o uso popular de plantas medicinais, contribuindo assim para o uso seguro e a descoberta de novos fármacos.

A Costus spicatus Jacq. S.w. (Costaceae/
Zinziberaceae), comumente chamada de Cana do Brejo no Brasil, é uma planta medicinal encontrada em florestas úmidas costeiras. O rizoma desta planta é usado para o tratamento das queixas da bexiga e uretra e para expulsar pedras nos rins. A infusão das partes aéreas é utilizada para tratar resfriados, dor na garganta, disenteria e diarreia (Silva et al, 2000) . Sua utilização na medicina tradicional ainda inclui o uso das folhas, hastes e rizomas como diurético e tônico (Lorenzi \& Matos, 2008).

A ação antioxidante das espécies de Costus ainda não está bem esclarecida. Contudo, estudos mostram que muitas espécies das Zinziberaceae

Recebido para publicação em 01/04/2013 
podem seqüestrar de radicais livres (Haraguchi et al, 1996).

Os radicais livres (RL) são moléculas com um elétron desemparelhado no último orbital, tornando-as muito instáveis, extraordinariamente reativas, e com enorme capacidade para combinarse com diversas moléculas integrantes da estrutura celular, como DNA, proteínas, carboidratos e lipídios (Gasparri, 2005). A capacidade de se combinar às estruturas celulares está associada a vários processos patológicos, tais como: câncer, arteriosclerose, e mal de Alzheimer, entre outras desordens, e ao processo normal do envelhecimento (Salvador \& Henriques, 2004).

Estudos químicos realizados com as partes aéreas da Costus spicatus permitiram o isolamento de novos diglicosídeos flavônicos, como a tamarixetina 3-O-neohesperidosídeo, o canferídio 3-O-neohesperidosídeo, seis flavonóides e outros compostos, como quercetina 3-O-neohesperidosídeo (Silva et al, 2000). Na sua composição química é registrada ainda a presença de ácido oxálico, taninos, saponinas, mucilagens, e pectinas (Vieira \& Alburqueque, 1998).

Muitos extratos de plantas que contêm compostos fenólicos, principalmente flavonóides e taninos, parecem apresentar significativa atividade antioxidante, capaz de diminuir os efeitos nocivos gerados pelos radicais livres (Gasparri, 2005). No entanto, também têm sido mostrado relatos sugerindo que uma dieta rica em compostos fenólicos exibe propriedades pró-oxidantes e citotóxicas, sob certas condições (Sugiyama et al, 2008).

Diante do exposto, o objetivo deste trabalho foi realizar a triagem fitoquímica e avaliar a atividade antioxidante de órgãos de Costus spicatus, visando contribuir com o conhecimento da flora medicinal, assim como fornecer informações para futuros projetos de pesquisa.

\section{MATERIAL E MÉTODO}

\section{O estudo foi descritivo.}

Foram utilizados caules, folhas e flores da Costus spicatus, colhidos na Universidade Estadual do Norte Fluminense Darcy Ribeiro, no município de Campos dos Goytacazes, RJ. A exsicata da espécie foi registrada na coleção do herbário da UENF.

O material foi seco à temperatura ambiente e conservado ao abrigo da luz e umidade. Após a secagem, o material foi submetido a uma trituração e extração exaustiva a temperatura ambiente em álcool $96^{\circ} \mathrm{GL}$ por 3 dias. Após, o extrato obtido foi filtrado e submetido a rotaevaporação de $8 \mathrm{rpm}$ em temperatura constante de $90^{\circ} \mathrm{C}$.
O extrato etanólico foi solubilizado em metanol/água (80:20) e submetido a partição líquidolíquido em hexano, acetato de etila e butanol. Em seguida as frações foram submetidas a ensaios de triagem fitoquímica e atividade antioxidante.

Para identificação de triterpenos e esteróides foram utilizados $2 \mathrm{mg}$ das frações dos extratos, solubilizados em $3 \mathrm{~mL}$ de clorofórmio, e em seguida, $2 \mathrm{~mL}$ de anidrido acético. Agitou-se suavemente e adicionou-se pelas paredes do tubo 5 gotas de ácido sulfúrico concentrado. Este resultado é observado pela reação de Lieberman-Burchard.

$\mathrm{Na}$ identificação para flavonóides, $2 \mathrm{mg}$ das frações foram dissolvidos em $5 \mathrm{~mL}$ de metanol e $1 \mathrm{~mL}$ de ácido clorídrico concentrado com a presença de $1 \mathrm{~cm}$ de fita de magnésio. Este resultado é observado pela reação de Shinoda ou cloreto de cianidina.

A verificação da presença de saponinas nas amostras foi realizada através do teste de espuma persistente, em que $2 \mathrm{~mL}$ das frações dos extratos foram solubilizados em $3 \mathrm{~mL}$ de água destilada e agitados em tubo de ensaio por 3 minutos.

Para determinação de alcalóides, 2 mg do extrato etanólico em tubo de ensaio foram alcalinizados com quinze gotas de hidróxido de sódio a $1 \%$ e acrescidos de $2 \mathrm{~mL}$ de água e $2 \mathrm{ml}$ de clorofórmio. A fração aquosa foi desprezada e a fração clorofórmica acrescida de quinze gotas de ácido clorídrico a 1\%, e em seguida extraída com 2 $\mathrm{mL}$ de água. A fração clorofórmica foi desprezada e os testes realizados com a fração aquosa ácida, acrescentando-se três gotas do reagente de Drangendorff para a verificação da presença de alcalóides.

A identificação de taninos foi realizada em tubo de ensaio contendo $2 \mathrm{mg}$ do extrato adicionando-se três gotas de solução alcoólica de $\mathrm{FeCl}_{3}$ e agitando fortemente.

As frações foram submetidas a avaliação da atividade antioxidante pelo método 1,1-difenil2-picrilhidrazila (DPPH), realizando-se uma leitura espectrofotométrica. Este método consiste em avaliar a atividade sequestradora do radical livre DPPH, de coloração violeta, que absorve em $515 \mathrm{~nm}$. Por ação de substância antioxidante o DPPH é reduzido formando difenil-picril-hidrazina de coloração amarela, com consequente desaparecimento da absorção, podendo a mesma ser monitorada pelo decréscimo da absorbância (Sousa et al, 2007). As amostras foram diluídas e avaliadas em triplicata com concentrações finais de $1000 \mu \mathrm{g} / \mathrm{ml}, 100 \mu \mathrm{g} /$ $\mathrm{ml}$ e $10 \mu \mathrm{g} / \mathrm{ml}$ em metanol e a mistura reacional agitada durante 1 hora à temperatura ambiente. $\mathrm{Na}$ leitura espectrofotométrica, foi realizado um teste em branco utilizando o metanol para calibração do espectrofotômetro. A análise de uma solução padrão (1:1) de DPPH em metanol foi realizada para

Rev. Bras. PI. Med., Campinas, v.16, n.2, p.209-215, 2014. 
obtenção de dados de absorbância sem as amostras $\left(A b s_{\text {controle }}\right)$ o qual será utilizado para o cálculo de atividade antioxidante.

Para comparações com referência de atividade antioxidante, foram realizadas análises utilizando o agente antioxidante BHT (Butil-hidroxitolueno) nas mesmas concentrações que a amostra.

Os valores de absorbância em todas as concentrações testadas foram convertidos em porcentagem de atividade antioxidante (AA), determinada pela equação:

$\% A A=\left\{\left(\mathrm{Abs}_{\text {controle }}-\mathrm{Abs}_{\text {amostra }}\right) \times 100\right\} / \mathrm{Abs}_{\text {controle }}$

Os resultados obtidos foram avaliados através do Programa Prisma.

\section{RESULTADOS}

Na determinação do perfil fitoquímico (Tabela 1), os testes mostraram a presença de triterpenos e esteróides apenas nas frações hexânica e acetato de etila da folha com o aparecimento de coloração azul evanescente seguida de verde. A presença de flavonóides foi constatada na folha em todas as frações pelo aparecimento de coloração vermelha, porém não foram encontrados nos demais órgãos. A presença de saponinas foi revelada apenas nas frações butanólicas da folha e caule após o aparecimento de espuma persistente. Quanto aos taninos, apenas nas frações butanólicas da flor e caule foi constatada presença pela formação de precipitado.

A avaliação da atividade antioxidante da flor está representada na Figura 1. Podemos observar que a fração que apresentou maior atividade antioxidante foi a de acetato de etila. As frações butanólica e hexânica apresentaram menor atividade, respectivamente. Para as frações acetato de etila e butanólica, as concentrações das amostras que apresentaram maior atividade foram a de $1,0 \mathrm{mg} / \mathrm{mL}$, enquanto para fração hexânica, a concentração que apresentou maior atividade foi a de $0,01 \mathrm{mg} / \mathrm{mL}$.

Quanto à atividade antioxidante da folha (Figura 2), a fração que apresentou maior atividade foi a butanólica. A fração acetato de etila e hexânica apresentaram menor atividade, respectivamente. Quanto às concentrações, tanto na fração butanólica, quanto na fração acetato de etila, a que apresentou a maior atividade foi a de $0,01 \mathrm{mg} / \mathrm{mL}$, enquanto na fração hexânica, a concentração com maior atividade foi a de $0,1 \mathrm{mg} / \mathrm{mL}$.

A avaliação da atividade antioxidante do caule (Figura 3) mostrou que a fração que possui maior atividade foi a hexânica. A fração acetato de etila e a fração butanólica apresentaram menor atividade, respectivamente. Em relação às concentrações, na

TABELA 1. Triagem fitoquímica de Costus spicatus

\begin{tabular}{|c|c|c|c|c|c|c|c|c|c|c|c|c|}
\hline & \multicolumn{4}{|c|}{ Flor } & \multicolumn{4}{|c|}{ Folha } & \multicolumn{4}{|c|}{ Caule } \\
\hline & Et & Hex & Act & But & Et & Hex & Act & But & Et & Hex & Act & But \\
\hline Triterpenos/ Esteróides & & $\cdot$ & $\cdot$ & $\cdot$ & & + & + & $\cdot$ & & $\cdot$ & $\cdot$ & $\cdot$ \\
\hline Flavonóides & & - & - & - & & + & + & + & & - & - & - \\
\hline Saponinas & & $\cdot$ & - & $\cdot$ & & - & $\cdot$ & + & & - & - & + \\
\hline Taninos & & $\cdot$ & $\cdot$ & + & & $\cdot$ & - & $\cdot$ & & $\cdot$ & - & + \\
\hline Alcalóides & + & & & & + & & & & + & & & \\
\hline
\end{tabular}

Et: ex trato bruto etanólico, Hex: Fração hexânica; Act: Fração acetato de etila; But: Fraçào butanólica

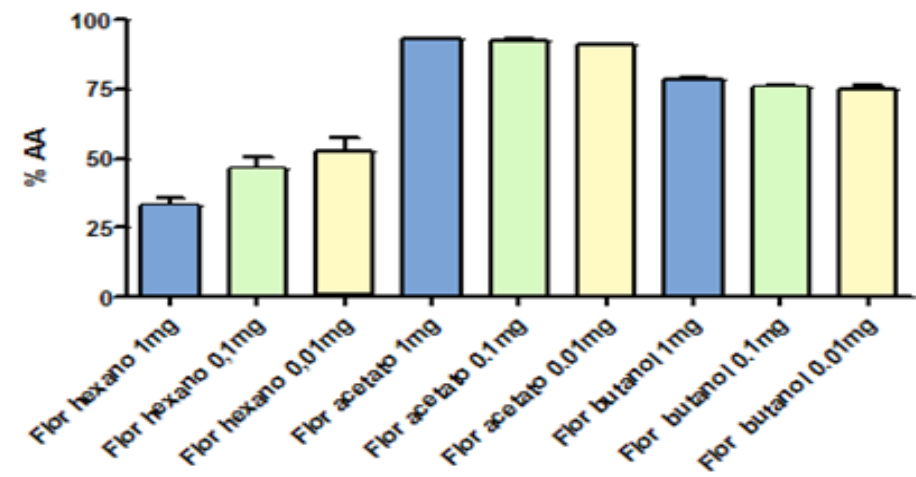

FIGURA 1. Atividade antioxidante da flor de Costus spicatus

Rev. Bras. PI. Med., Campinas, v.16, n.2, p.209-215, 2014. 


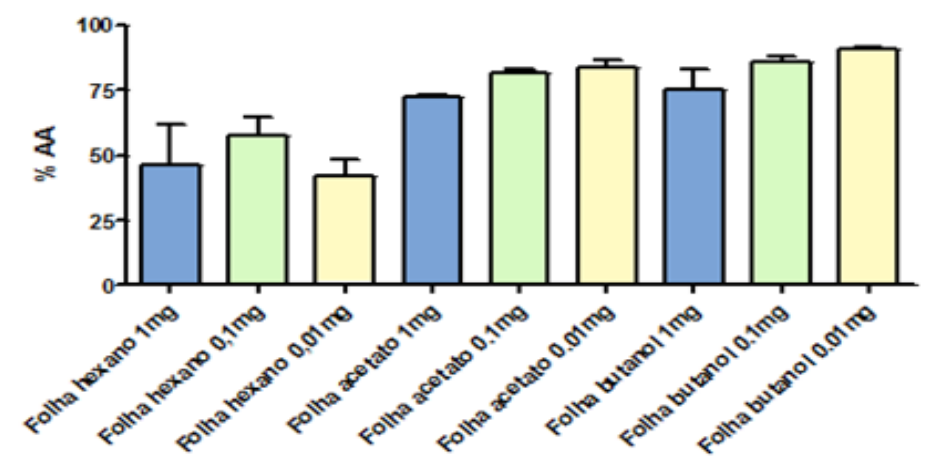

FIGURA 2. Atividade antioxidante da folha de Costus spicatus

fração hexânica, as concentrações de $1 \mathrm{mg} / \mathrm{mL}$ e 0,1 $\mathrm{mg} / \mathrm{mL}$ apresentaram atividades próximas, sendo a concentração de $0,1 \mathrm{mg} / \mathrm{mL}$ ligeiramente maior. $\mathrm{Na}$ fração acetato de etila, a concentração que mostrou maior atividade foi a de $0,01 \mathrm{mg} / \mathrm{mL}$, enquanto na fração butanólica, a maior atividade foi detectada na concentração de $0,1 \mathrm{mg} / \mathrm{mL}$.

O padrão BHT após ser submetido ao teste apresentou, na concentração de $1 \mathrm{mg} / \mathrm{mL}, 90,2 \%$, de atividade antioxidante. Nas concentrações de $0,1 \mathrm{mg} / \mathrm{mL}$ e $0,01 \mathrm{mg} / \mathrm{mL}$ apresentou $57,1 \%$ e $33,9 \%$ de atividade respectivamente.

\section{DISCUSSÃO}

$\mathrm{Na}$ determinação do perfil fitoquímico (Tabela 1), foi detectada na flor a presença de alcalóides no extrato etanólico bruto pela formação de precipitado floculoso. Isso ocorre porque os alcalóides, semelhante a outras aminas, formam sais complexos obtidos na forma de precipitados em soluções alcalinas ou levemente ácidas pelo reagente de Dragendorff (Simões, 2007). Foram encontrados também taninos na fração butanólica pela formação de precipitado. Isso ocorre porque estes compostos possuem habilidade de formar complexos insolúveis em água com alcalóides, gelatinas e metais (Costa, 2002). Os taninos se distribuem em padrões diferentes no reino vegetal.
Os taninos hidrolisáveis estão quase restritos às Choripetalae das dicotiledôneas, enquanto as proantocianidinas (taninos condensados) podem aparecer em Angiospermae, especialmente em plantas lenhosas (Robbers et al, 1997), o que pode indicar que a Costus spicatus apesar de não possuir características de plantas ricas em taninos (lenhosas), por pertencer a divisão da Angiospermae, pode possuir essa classe de metabólitos secundários. $O$ aparecimento de taninos nesta fração pode ser justificado pelo fato de serem compostos fenólicos, solúveis, portanto em água e solventes orgânicos polares (Oliveira et al, 2005).

Em relação à folha, também foram encontrados alcalóides no extrato etanólico pela formação de precipitado. Os alcalóides podem ser encontrados em todas as partes de um vegetal, porém, em um ou mais órgãos, haverá acúmulo preferencial (Simões, 2007). Triterpenos/esteróides foram detectados na fração hexânica e acetato de etila pelo aparecimento de cor azul evanescente seguida de verde. Isso ocorre porque tanto os triterpenóides, quanto os esteróides, são compostos apolares, podendo aparecer, portanto, em solventes apolares, como o hexano, ou, em menor quantidade, em solventes de polaridade intermediária, como $o$ acetato de etila. A presença de flavonóides foi detectada nas três frações pelo aparecimento de cor vermelha. A extração com solventes menos

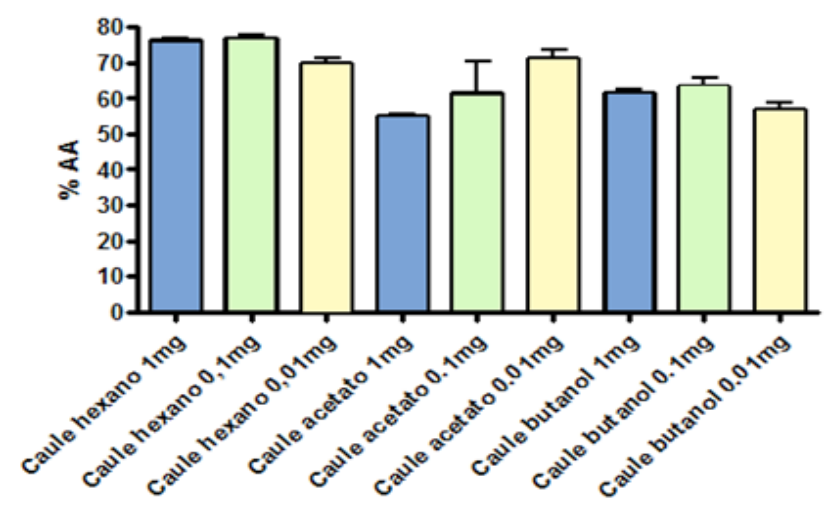

FIGURA 3. Atividade antioxidante do caule de Costus spicatus 
polares (hexano e acetato de etila) permite recuperar agliconas livres pouco polares, como flavonas, flavonois e flavanonas e, na sequência, o uso do $n$-butanol permite a obtenção dos heterosídeos (flavonóides ligados a açúcares) (Yunes \& Calixto, 2001). Também foi detectada a presença de saponinas na fração butanólica pela formação de espuma persistente. Essa propriedade das saponinas é decorrente da sua estrutura que possui uma parte lipofílica (aglicona ou sapogenina) e uma parte hidrofílica constituída por um ou mais açúcares (Costa et al, 2010). A presença de saponinas na fração butanólica pode ser justificada pelo fato de serem glicosídios e, portanto, substâncias polares (Monteiro et al, 2005).

Quanto ao caule, o extrato etanólico, assim como nos demais órgãos, apresentou alcalóides. Apesar de raramente estarem presentes em tecidos mortos como cascas, os alcalóides podem, em menores concentrações, ser encontrados no parênquima (Simões, 2007), justificando sua presença no órgão. Dos demais metabólitos secundários pesquisados, apenas saponinas e taninos foram encontrados na fração butanólica. A presença de compostos fenólicos nos vegetais, especialmente os taninos, tem reconhecida função de inibir herbívoros, pois tornam os tecidos impalatáveis aos fitófagos, conferindo sabor adstringente (Santos \& Blatt, 1998).

$\mathrm{Na}$ avaliação da atividade antioxidante, observa-se na Figura 1 que a fração hexânica da flor apresentou uma atividade moderada. Porém, na triagem fitoquímica, não foi detectada a presença de nenhuma das classes de metabólitos secundários pesquisadas, o que demonstra a presença de outros compostos não pesquisados nessa fração responsáveis pela atividade antioxidante. Pode ser observada nessa mesma fração que a atividade antioxidante das amostras nas concentrações de $1 \mathrm{mg} / \mathrm{mL}, 0,1 \mathrm{mg} / \mathrm{mL}$ e $0,01 \mathrm{mg} / \mathrm{mL}$ pareceu aumentar com as diluições. É possível que a cor de algumas amostras interfira na leitura espectrofotométrica, que não associa a intensidade da cor à elevada atividade antioxidante, não refletindo, portanto exatamente a atividade antioxidante de amostras muito coloridas. Outro estudo observou que uma concentração alta das amostras pode interferir no resultado, pois apresenta forte coloração, interferindo na leitura espectrofotométrica, extrapolando assim os valores de absorbância, sendo necessária a diluição destas para a realização da leitura (Filho, 2010).

$\mathrm{Na}$ fração acetato de etila da flor, nenhuma das classes de metabólitos pesquisadas foram encontradas, indicando que outro composto é o responsável pela elevada atividade antioxidante observada. Verificou-se também que nesta fração não ocorreu interferência da cor, possibilitando, portanto, a observação da ligeira diminuição da atividade antioxidante em relação ao aumento da diluição.

Quanto a fração butanólica da flor, a atividade antioxidante observada pode ser devido a presença de taninos detectados nessa fração. Alguns autores descrevem que os taninos possuem elevada atividade antioxidante (Pessanha, 2010) e são encontrados em maior quantidade no súber de plantas lenhosas, porém, podem aparecer também em folhas e flores (Robbers et al, 1997). Assim, a Costus spicatus, por não ser lenhosa, não possui características de plantas ricas em taninos e sua atividade antioxidante observada na fração butanólica pode ser devido a um sinergismo com outra classe de metabólito aqui não pesquisada.

A atividade antioxidante observada na flor apresentou-se maior na fração acetato de etila, reforçando a necessidade de se ampliar o estudo para outras classes de metabólitos que podem ser responsáveis por essa atividade. Quando comparada ao BHT como padrão externo de atividade antioxidante nas mesmas concentrações descritas na literatura (Filho, 2010), a fração acetato de etila da flor apresenta uma atividade antioxidante, semelhante ao padrão nas concentrações de 1,0 $\mathrm{mg} / \mathrm{mL}$ e $0,1 \mathrm{mg} / \mathrm{mL}$ e superior na concentração de $0,01 \mathrm{mg} / \mathrm{mL}$.

Em relação à folha, tanto na fração hexânica, quanto na fração acetato de etila, foram detectados triterpenos/esteróides e flavonóides. Esses flavonóides podem ser os responsáveis pela atividade antioxidante observada nessas frações (Figura 2). No entanto, as frações mais polares (acetato de etila e butanólica) apresentaram atividade antioxidante mais elevada. Isso pode ser devido ao fato de os flavonóides serem derivados fenólicos polares (Yunes \& Calixto, 2001) e solúveis, portanto, em solventes mais polares.

$\mathrm{Na}$ fração butanólica, foram encontrados flavonóides e saponinas. Os flavonóides dessa fração, assim como nas demais frações em que apareceram, são os possíveis responsáveis pela atividade antioxidante observada. $\mathrm{A}$ atividade antioxidante dessa fração se mostrou maior que a das demais, o que pode ser explicado pela maior solubilidade dos flavonóides em solventes polares como o butanol. Ao relacionar a atividade antioxidante da fração butanólica da folha com a do BHT, observa-se uma atividade antioxidante superior do padrão descrito, uma vez que a fração de menor concentração $(0,01 \mathrm{mg} / \mathrm{mL})$ apresentou atividade semelhante a do padrão em sua maior concentração $(1,0 \mathrm{mg} / \mathrm{mL})$.

Quanto à avaliação da atividade antioxidante do caule (Figura 3), as frações hexânica e acetato de etila apresentaram as maiores atividades,

Rev. Bras. PI. Med., Campinas, v.16, n.2, p.209-215, 2014. 
contudo, nenhuma das classes de metabólitos secundários pesquisadas foram encontradas, o que indica a presença de outra substância responsável pela atividade. Observa-se que na fração hexânica não ocorreu interferência da cor na leitura espectrofotométrica, no entanto, o mesmo ocorreu na fração acetato de etila.

A mesma interferência de cor observada na fração acetato de etila ocorreu na fração butanólica, porém apenas na concentração de 1,0 $\mathrm{mg} / \mathrm{mL}$, demonstrando que a diluição minimiza a intensidade da cor, facilitando assim a leitura espectrofotométrica. A atividade antioxidante observada nessa fração pode ser devido à presença de taninos detectados (tabela 1), todavia, não é característico dessa planta possuir quantidades elevadas de taninos, o que pode representar a presença de outra substância antioxidante nesta fração, levando a um sinergismo de ação. A título de comparação, pode-se observar que a fração do caule que apresentou maior atividade antioxidante foi a hexânica, sendo necessário, mais uma vez, ampliar a pesquisa do perfil fitoquímico para outras classes de metabólitos. Comparando-se a atividade antioxidante da fração hexânica do caule aos padrões descritos na literatura nas mesmas concentrações, pode-se demonstrar uma boa atividade antioxidante, porém inferior a dos padrões descritos nas concentrações de $1,0 \mathrm{mg} / \mathrm{mL}$ e 0,1 $\mathrm{mg} / \mathrm{mL}$ e superior na concentração de $0,01 \mathrm{mg} / \mathrm{mL}$.

Comparando-se a atividade antioxidante entre os três órgãos (flor, folha e caule), observa-se que a fração hexânica do caule apresentou maior atividade em relação à mesma fração dos demais órgãos. Em relação à fração acetato de etila, a que apresentou maior atividade antioxidante foi a da flor, superando a atividade da folha, na qual foi detectada a presença de flavonóides, compostos fenólicos com atividade antioxidante conhecida. Quanto à fração butanólica, a que apresentou maior atividade antioxidante foi a da folha, o que pode ser explicado pela presença de flavonóides encontrados nessa fração, uma vez que os flavonóides e outros derivados fenólicos são conhecidos por atuarem na captura e neutralização de espécies oxidantes (Gasparri, 2005).

\section{CONCLUSÃO}

O presente estudo, através da triagem fitoquímica, demonstrou que a Costus spicatus apresentou todas as classes de metabólitos pesquisadas, algumas com atividade biológica já conhecida, fazendo-se necessária a realização de estudos quantitativos e pesquisas que demonstrem seus efeitos farmacológicos, o que irá contribuir para o desenvolvimento de novos fármacos.
Contudo, a distribuição das classes de metabólitos secundários pesquisados mostrou-se diferente nos três órgãos analisados. A análise da atividade antioxidante permitiu a demonstração de uma boa atividade, quando comparada ao BHT como padrão externo. Entretanto, mostrou-se diferente entre as três frações analisadas dentro do mesmo órgão, e entre as mesmas frações de órgãos diferentes, evidenciando que a classe e distribuição de metabólitos responsáveis pela atividade são diferentes entre essas frações. Em algumas frações, foi observada elevada atividade antioxidante, porém nenhuma classe de metabólitos pesquisada foi encontrada, o que demonstra a presença de outras substâncias nessas frações responsáveis pela atividade e reforça a necessidade de se ampliar o estudo fitoquímico da Costus spicatus para outras classes. A avaliação da atividade antioxidante em algumas frações sofreu interferência da intensidade da cor da amostra, demonstrando que a técnica espectrofotométrica para avaliar tais atividades não é a mais indicada, devendo ser usadas outras técnicas descritas em literatura.

\section{REFERÊNCIA}

COSTA, A. F. Farmacognosia. v.1. 6 ed. Lisboa: Fundação Calouste Gulbenkian, 2002, p. 202-315.

COSTA, D. A.; CHAVES, M. H.; SILVA, W. C. S.; COST, CHAARLLYTON, L. S. Constituintes químicos, fenóis totais e atividade antioxidante de Sterculia striata St. Hil. et Naudin.Acta Ama, v.40, n.1, p. 207-2012, 2010.

FILHO, R.B. Contribuição da fitoquímica para o desenvolvimento de um país emergente. Química Nova, v. 33, n. 1, 2010.

GASPARRI, S. Estudo das atividades antioxidante e mutagênica/antimutagênica induzidas pelo extrato vegetal da Costus spicatus. 2005. 79 p. Dissertação (Mestrado em Diagnóstico Genético e Molecular) Universidade Luterana do Brasil, Canoas.

HARAGUCHI, H., KUWATA, Y., INADA, K., SHINGU, K., MIYAHARA, K., NAGAO, M., YAGI, A. Antifungal activity from Alpinia galanga and the composition for incorporation of unsaturated fatty acid in cell growth. Planta Medica, v. 62, p. 308-313, 1996.

LORENZI, H.; MATOS, F.J.A. Plantas medicinais no Brasil: nativas e exóticas. 2. ed. São Paulo: Instituto Plantarum, 2008. p. 512.

MONTEIRO, J. M.; ALBUQUERQUE, U. P.; ARAUJO, E. L.; AMORIM, E. L. C. Taninos: uma abordagem da química à ecologia. Química Nova, v. 28, n. 5, p. 892896, 2005.

OLIVEIRA, F.;AKISUE, G.;AKISUE, M. K. Farmacognosia. São Paulo: Atheneu, 2005, p. 114-208.

PESSANHA, F. F. Eugenia uniflora L. (Myrtaceae): caracterização e avaliação dos compostos fenólicos, da vitamina $\mathbf{C}$ e da atividade antioxidante dos frutos da pitangueira. 2010. 113 p. Tese (Mestrado em Produção Vegetal) - Universidade Estadual do Norte 
Fluminense Darcy Ribeiro, Campos dos Goytacazes.

REZENDE, J.R.; RODRIGUES, S.B.; JABOR, I.A.S.; PAMPHIIE, J.A.; ROCHA, L.M.S.C.; Efeito antimutagênico do látex de Euphorbia tirucalli no sistema metionina em Aspergillus nidulans. Acta Scientiarum Biological Sciences., v. 26, n.4, p. 481-484, 2004.

ROBBERS, J. E.; SPEEDIE, M.; TYLER, V. E. Farmacognosia e farmacobiotecnologia. São Paulo: Premier,1997, p. 132-210.

SALVADOR, M., HENRIQUES, J.A.P. Radicais livres e a resposta celular ao estresse oxidativo. $1 \mathrm{ed}$. Editora da ULBRA, Canoas, 2004. 200p.

SANTOS, M. D.; BLATT, C. T. T. Teor de flavonóides e fenóis totais em folhas de Pyrostegia venusta Miers. de mata e de cerrado.Revista Brasileira Botânica, v. 21, n. 2, 1998.

SILVA, B. P., BERNARDO, R. R., PARENTE, J. P. Flavonol glycosides from Costus spicatus. Phytochemistry v. 53, p. 87-92, 2000.

SIMÕES, C. M. O. (Org). Farmacognosia: da planta ao medicamento. 6 ed. Porto Alegre: Ed. da UFRGS, 2007, p 547-602.

SOUSA, C. M. M.; ROCHA E SILVA, H.; VIEIRA JR. G. M.; AYRES, M. C. C.; COSTA, C. L. S.; ARAÚJO, D. S.; CAVALCANTE, L. C. D.; BARROS, E. D. S.; ARAÚJO, P. B. M.; BRANDÃO, M. S.; CHAVES, M. H. (2007). Fenóis totais e atividade antioxidante de cinco plantas medicinais. Química Nova, v. 30, n. 2, p. 351 - 355, 2007.

SUGIYAMA, K-I., IZAWA, S., INOUE, Y. The Yap1pdependent induction of glutathione synthesis in heat shock response of Saccharomyces cerevisiae. Journal of Biological Chemistry, v. 275, p. 15535-15540, 2000.

VIEIRA, L.S., ALBUQUERQUE, J.M. Fitoterapia Tropical - Manual de Plantas Medicinais. FCAP - Serviço e Documentação e Informação. Belém, 1998.

YUNES, R. A.; CALIXTO, J. B. Plantas medicinais sob a ótica da química medicinal moderna: métodos de estudo: fitoterápicos e fitofármacos: biotecnologia: patente, 2001, p. 98-102. 